Article

\title{
The Ecosystem Effects of Sand-Binding Shrub Hippophae rhamnoides in Alpine Semi-Arid Desert in the Northeastern Qinghai-Tibet Plateau
}

\author{
Lihui Tian ${ }^{1,2, *}$, Wangyang $\mathrm{Wu}^{3}$, Xin Zhou ${ }^{1}$, Dengshan Zhang ${ }^{2}$, Yang Yu ${ }^{4}$, Haijiao Wang ${ }^{1}$ and \\ Qiaoyu Wang ${ }^{1}$ \\ 1 State Key Laboratory of Plateau Ecology and Agriculture, Qinghai University, Xi'ning 810016, China; \\ 18797328039@163.com (X.Z.); wbdxdaq@126.com (H.W.); m15297084668@163.com (Q.W.) \\ 2 Qinghai Academy of Agricultural Forestry Sciences, Qinghai University, Xi'ning 810016, China; \\ dshzhang@bnu.edu.cn \\ 3 School of Earth Sciences, East China University of Technology, Nanchang 200237, China; \\ wuwangyang@ecit.cn \\ 4 Department of Sediment Research, China Institute of Water Resources and Hydropower Research, \\ Beijing 100038, China; theodoreyy@gmail.com \\ * Correspondence: lhtian@qhu.edu.cn
}

Received: 6 November 2019; Accepted: 27 November 2019; Published: 29 November 2019

\begin{abstract}
The planting of sand-binding vegetation in the Qinghai Lake watershed at the northeastern edge of the Qinghai-Tibet Plateau began in 1980. For this paper, we took the desert on the eastern shore of Qinghai Lake as the study area. We analyzed a variety of aged Hippophae rhamnoides communities and aeolian activities, and we discuss the relationship between them. The main conclusions are as follows: (1) With an increasing number of binding years, the species composition became more abundant, natural vegetation began to recover, and biodiversity increased year by year. At the same time, plant height, canopy width, and community coverage increased, but $H$. rhamnoides coverage was reduced to $36.70 \%$ as coverage of Artemisia desertorum increased to $25.67 \%$ after 10 years of fixing. The biomass of $H$. rhamnoides increased significantly, especially the underground biomass. For example, the biomass of area 15a was about 10 to 30 times that of area 1a. (2) Plants are a useful obstacle to aeolian activity. The presence of plants reduced the wind flow in the upper parts of the plants, but it did not have obvious regular characteristics. The longer the fixation term, the lower the surface sediment transport. It is significant that the sediment transport amount in winter was four times that in the summer. After 15 years of binding, H. rhamnoides grows well, and the community is still stable in the study area.
\end{abstract}

Keywords: desert around the Qinghai Lake; vegetation restoration; Hippophae rhamnoides; aeolian activities

\section{Introduction}

Desertification is one of the world's most serious environmental problems and has attracted worldwide attention [1,2]. Vegetation restoration is a critical and effective measure to control desertification and recover degraded ecosystems [3]. The establishment of sand-binding vegetation is one of the main techniques for ecological restoration in arid and semi-arid zones, and this method has been widely used in desert regions around the world and is one of the most effective ways to combat desertification [4]. China has used sand-binding vegetation to combat desertification for almost 60 years [5]. Shrubs are the main sand-binding pioneer species for their extensive coverage and strong protective performance in spring. In the practice of planting sand-binding vegetation in a desert, the 
success of the vegetation restoration primarily depends on the adaptability of the pioneer sand-binding plants to the microenvironment. However, there have been few studies examining how different aged introduced sand-binding shrubs adapt to the cold and dry environment in sandy alpine areas. It is necessary to carry out research on the relationship between sand-binding shrubs and aeolian activities in alpine areas so that artificial plant communities can gradually evolve into stable natural plant communities, achieving long-term ecosystem effects.

Hippophae rhamnoides is a dioicous, deciduous, thorny shrub that has a wide distribution across Europe to Asia; it is a coastal species in northwest Europe and is found in mountain ranges from the Pyrenees to the Himalayas [6]. It has an extensive horizontal root structure that forms frequent, rapidly growing aerial parts, and shoots have been shown to achieve $70 \mathrm{~cm}$ growth per year [6]. Its high survivorship is closely linked to the rapid growth of its root systems, which are highly flexible and adapt to various soil water conditions [7]. H. rhamnoides is mainly distributed in the Loess Plateau and scattered across Qinghai Plateau in China, where it has a natural distribution in the eastern shore of the Qinghai Lake with no typical community. So, it has been used for afforestation in the Qinghai Lake desert region to fix shifting sands since 1980. The Mu Us desert is one of the typical distribution areas of $H$. rhamnoides, but research on $H$. rhamnoides in this area mainly includes dynamic population changes, reproductive proliferation, and the relationship with soil water content [8], while few studies have paid attention to the relationship between community features and aeolian activities. As a typical sand-binding plant in a sandy alpine land, the systematic research on $H$. rhamnoides is still weak.

The wind-sand-vegetation ecosystem is an essential aspect in desert ecology and desertification control [9]. The intensity of aeolian activity directly affects the growth of sand-binding vegetation and community succession. When plant stems, leaves, and roots are subjected to wind-blown sand and wind erosion separately, they will have different degrees of physiological responses [10,11]. The aeolian activity has a dual effect on the growth of desert plants. On the one hand, sand carried by strong winds hits plant stems and leaves, finally adhering as dust and affecting the respiration of plants; on the other hand, different degrees of sand burial of plants affect the survival and growth of underground rhizomes [12]. Strong aeolian activities will directly reduce the plant seedling survival rate, reproduction rate, and growth state and community stability, while moderate wind erosion the sand burial will promote the regeneration of underground rhizomes, high plant growth, and fertility, thereby promoting community succession. Against the hazards of wind-blown activities, desert plants have usually adapted through morphological transformation, reproductive strategies, respiratory regulation, and water and nutrient redistribution $[13,14]$. However, the current research has always been based on a single environmental control experiment, lacking field verification, and special environmental considerations. At the same time, the research objects are mainly based on the short-term ecological response of an individual plant, and examinations of the plant community response and long-term change response are insufficient. In addition, the study of the response mechanism of desert plants to wind-blown hazards lacks practical guidance for desertification control work, and field observation experiments are needed to guide suitable site conditions, afforestation structures, and methods or species allocation for artificial sand-binding plants.

Plantations face strong aeolian activities in alpine deserts, which are severely endangered by ecological fragility, species scarcity, and desertification. At present, an increasing number of afforestation vegetation has appeared to die or undergo poor growth in alpine sandy areas. The vegetation protection efficiency has decreased year by year with the decline in growth, which has resulted in the mutation of the vegetation community and activation of fixed dunes. The growth potential and sand control effect are inhibited under the low temperature and high wind velocity in alpine desert regions, which are different from the arid and semi-arid deserts in the north of China. Qinghai Lake is one of the typical ecologically fragile areas of the Qinghai-Tibet Plateau, and although H. rhamnoides has been planted in the Qinghai Lake watershed for more than 30 years, the research on this vegetation restoration is extremely lacking, especially the relationship between the plant community and aeolian activity. The existing research on vegetation and wind has mainly focused on the attenuation of surface sand 
activity after afforestation [15], soil improvement [16], plant community changes [17], and water source use on a site scale [18].

Therefore, in this paper, we intend to discuss the relationship between sand-binding plants and aeolian activities by taking aged $H$. rhamnoides planted in different years on the eastern shore of the Qinghai Lake as a case, in order to provide theoretical guidance for desertification control in alpine desert regions. We hypothesized that the desert habitat is improved with restoration.

\section{Materials and Methods}

\subsection{Study Area}

The study was conducted in the Ketu Wind Prevention and Sand Fixation Experimental Range (hereafter, WPSER; 36 $46.9^{\prime} \mathrm{N}, 100^{\circ} 46.8^{\prime} \mathrm{E}, 3224 \mathrm{~m}$ elevation (above sea level) a.s.l.) in the southeast corner of Haiyan Bay, blocked by the Ruiyue and Tuanbao Mountains on the eastern shore of Qinghai Lake (Figure 1). Mega-dunes and continuous mobile dunes are distributed in WPSER. The field is primarily composed of short barchans and transversal sand ridges which stand on average 6-10 m high and stretch from the north to the south. Since the early 1980s, the local government has taken measures to prevent mobile dunes in the west district, and now a large area of shifting dunes has been fixed with straw checkerboards and shrubs.

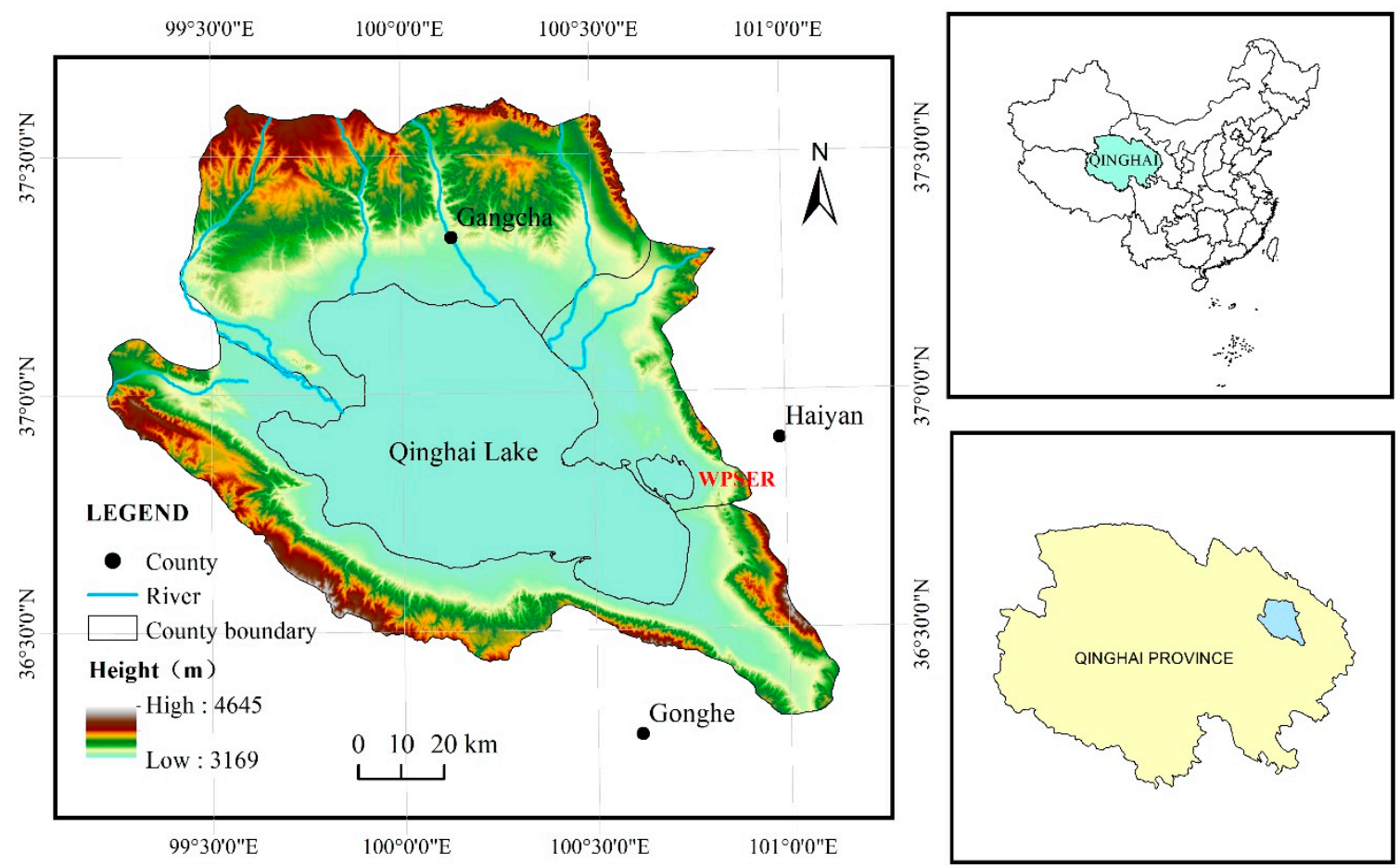

Figure 1. Geographic location of the study area.

WPSER belongs to an alpine semi-arid climatic zone with relatively wet summers and cold winters. Based on data from the Haiyan County National Meteorological Station (2006-2017), which is approximately $20 \mathrm{~km}$ away from WPSER, the annual mean temperature is $0.7^{\circ} \mathrm{C}$, with the lowest mean monthly temperature in January $\left(-11.76^{\circ} \mathrm{C}\right)$ and the highest in July $\left(14.97^{\circ} \mathrm{C}\right)$. The annual average precipitation is $370 \mathrm{~mm}$, approximately $80 \%$ of which occurs from June to September. The mean annual pan evaporation is $1483.9 \mathrm{~mm}$. According to sandstorm observations from the past five years, the strongest period of sandstorm activity is during late autumn to early spring, controlled by SW-W-NW wind directions, and the mean wind speed is $5.5 \mathrm{~m} \cdot \mathrm{s}^{-1}$. According to our field observations, sediment 
transport is the highest in spring, and the annual synthetic drift potential (DP) is 88.69 , classifying it as a low wind energy environment.

During the past 10 years, from 2008 to 2017, all forest land formed a vegetation community dominated by plantations, and large-scale mobile sand dunes gradually transformed into semi-fixed or fixed dunes [17]. We selected five dunes planted with H. rhamnoides and a mobile dune (LSD) in WPSER as the study sites (Table 1 and Figure 2). All of dunes are barchans, and our objects were only the communities at the top of dunes. The groundwater level at the study sites ranged from $8 \mathrm{~m}$ to $15 \mathrm{~m}$ for different dunes.

Table 1. Features of aged Hippophae rhamnoides in the study area.

\begin{tabular}{|c|c|c|c|c|c|c|}
\hline No. & $\begin{array}{l}\text { Planting } \\
\text { Time }\end{array}$ & $\begin{array}{c}\text { Original } \\
\text { Topography }\end{array}$ & $\begin{array}{c}\text { Existing } \\
\text { Topography }\end{array}$ & $\begin{array}{c}\text { Dune } \\
\text { Height } / \mathrm{m}\end{array}$ & $\begin{array}{c}\text { Mechanical } \\
\text { Barriers }\end{array}$ & $\begin{array}{l}\text { Afforestation } \\
\text { Mode }\end{array}$ \\
\hline $1 \mathrm{a}$ & 2016 & Mobile dune & Mobile dune & 10.3 & $\begin{array}{c}\text { Barley-oat } \\
\text { checkerboards }\end{array}$ & Seedlings \\
\hline $3 a$ & 2014 & Mobile dune & Mobile dune & 8.7 & $\begin{array}{c}\text { Straw } \\
\text { checkerboards }\end{array}$ & Seedlings \\
\hline $5 a$ & 2012 & Mobile dune & $\begin{array}{l}\text { Semi-fixed } \\
\text { dune }\end{array}$ & 7.2 & $\begin{array}{c}\text { Straw } \\
\text { checkerboards }\end{array}$ & Seedlings \\
\hline $10 a$ & 2008 & Mobile dune & Fixed dune & 10.6 & $\begin{array}{c}\text { Straw } \\
\text { checkerboards }\end{array}$ & Seedlings \\
\hline $15 a$ & 2003 & Mobile dune & Fixed dune & 5.9 & $\begin{array}{c}\text { Straw } \\
\text { checkerboards }\end{array}$ & Seedlings \\
\hline LSD & Natural & Mobile dune & Mobile dune & - & - & - \\
\hline
\end{tabular}

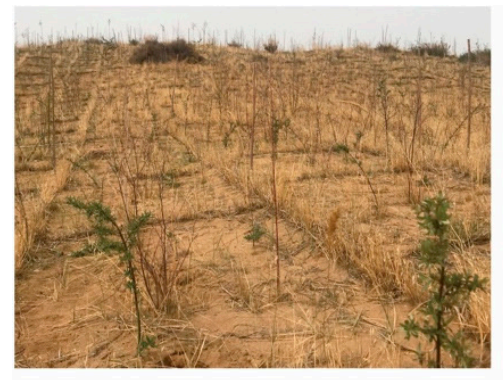

$1 a: 36^{\circ} 46^{\prime} 30^{\prime \prime} \mathrm{N}, 100^{\circ} 46^{\prime} 40^{\prime \prime} \mathrm{E}, 3238 \mathrm{~m}$

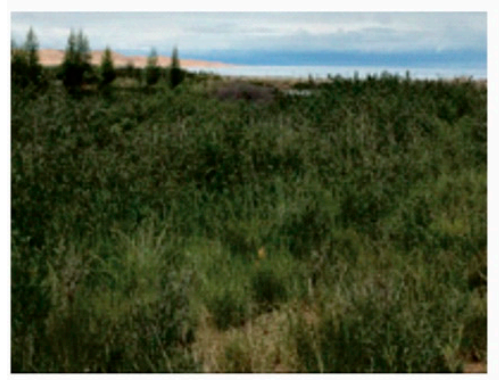

$10 a: 36^{\circ} 46^{\prime} 55^{\prime \prime} \mathrm{N}, 100^{\circ} 46^{\prime} 54^{\prime \prime} \mathrm{E}, 3230 \mathrm{~m}$

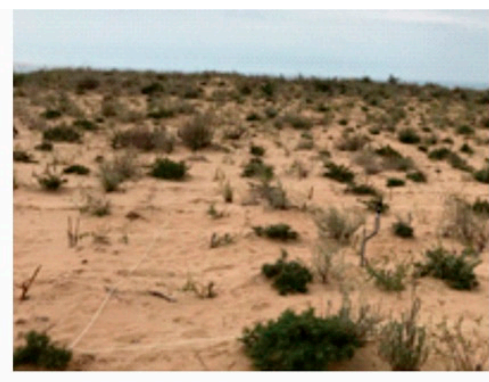

$3 a: 36^{\circ} 47^{\prime} 07^{\prime \prime} N, 100^{\circ} 47^{\prime} 27^{\prime \prime} E, 3250 m$

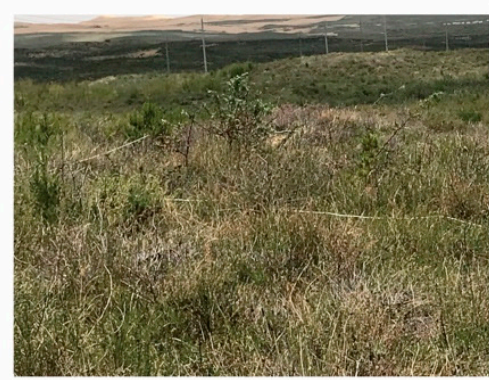

$15 a: 36^{\circ} 47^{\prime} 03^{\prime \prime} N, 100^{\circ} 46^{\prime} 56^{\prime \prime} E, 3223 m$

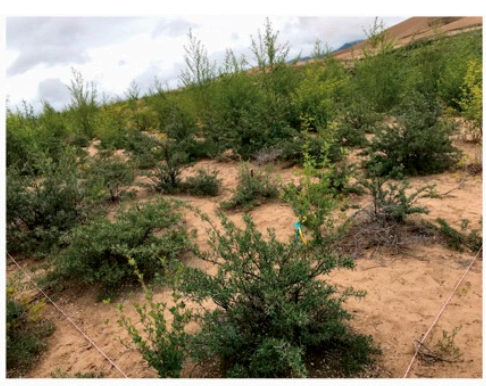

$5 a: 36^{\circ} 47^{\prime} 05^{\prime \prime} N, 100^{\circ} 47^{\prime} 14^{\prime \prime} E, 3233 m$

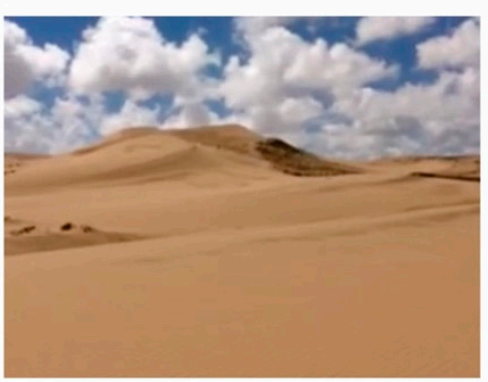

$L S D: 36^{\circ} 47^{\prime} 05^{\prime \prime} N, 100^{\circ} 47^{\prime} 33^{\prime \prime} E, 3250 m$

Figure 2. Photos of the study sites

\subsection{Plant Feature Investigation and Analysis}

The survey area of the shrubs was $5 \mathrm{~m} \times 5 \mathrm{~m}$, whereas that of herbs was $1 \mathrm{~m} \times 1 \mathrm{~m}$. The plant number, height, and coverage for each species in the sand stabilization areas from different years were recorded or measured. In this study, the Simpson index D, Shannon-Wiener index $\mathrm{H}^{\prime}$, and Pielou evenness index J were used to measure the diversity of plants [19]:

$$
D=1-\sum p_{i}^{2}
$$




$$
\begin{gathered}
H^{\prime}=-\sum p_{i} \ln p_{i} \\
J=H^{\prime} / \ln S
\end{gathered}
$$

where $p_{i}$ is the relative importance value (IV) of species $i$ (relative height + relative coverage), and $S$ is the total number of species $i$ in the quadrat, that is, an abundance index.

We used the trenching method to investigate the root biomass and distribution. Six trenches were made in each sampling plot in early August 2017 (two trenches per quadrat, three quadrats per plot). Roots were separated from the soil by washing through a $0.5 \mathrm{~mm}$ sieve and sorted into coarse $(>2 \mathrm{~mm}$ diameter) and fine ( $<2 \mathrm{~mm}$ diameter) fractions. Roots with diameters of $<2 \mathrm{~mm}$ were generally defined as feeder roots for water and mineral uptake. Roots were then stored in paper bags until oven-drying at $60^{\circ} \mathrm{C}$ for $48 \mathrm{~h}$ to a constant weight. Root biomass is expressed on a ground area basis $\left(\mathrm{kg} \cdot \mathrm{m}^{-2}\right)$.

\subsection{Aeolian Activity Investigation and Analysis}

In the spring, summer, and autumn of 2018, hand-held anemometers (Kestrel NK5500, USA) were used at heights of $0.5 \mathrm{~m}$ and $2 \mathrm{~m}$ to observe the wind speed. The sampling frequency of the data acquisition was 1 time. $\mathrm{min}^{-1}$, the flat top of the mobile dune was used as the control point, and the tops of dunes planted with $H$. rhamnoides with different growth years $(1 a, 3 a, 5 a, 10 a$, and 15a) were used as flow points. Each site was measured with three to five replications. The wind measurement period was from 10:00 to 19:00, and the sampling frequency of the data collection was 10 times. $\mathrm{min}^{-1}$. The wind speed $\left(\mathrm{V}^{\prime}(\mathrm{z})\right)$ of each flow point was standardized using wind speed data from the control point in order to compare the wind conditions of the aged H. rhamnoides communities at the same time. Then, we calculated the wind increase rate $\left(\mathrm{R}, \mathrm{m} \cdot \mathrm{s}^{-1}\right)[20]$ :

$$
R=\frac{V_{2-} V_{1}}{H} \times 100 \%
$$

where $H$ is the height difference for $Z_{1}$ and $Z_{2}$, and $V_{1}$ and $V_{2}$ are the wind velocities at heights $Z_{1}$ and $Z_{2}$, respectively. We divided the height of $2 \mathrm{~m}$ into two layers: bottom $(0-1.0 \mathrm{~m})$ and upper $(1.0-2.0 \mathrm{~m})$.

From January 2018, we set nine sand-collecting bottles ( $65 \mathrm{~mm}$ high and $45 \mathrm{~mm}$ in diameter) in strips at each study site for the entire year of 2018. The sand was moved to plastic Ziploc bags, brought back to the laboratory, and impurities were removed for drying and weighing every month. The 12-month surface sediment data recorded in 2018 were divided into four seasons (spring/summer/autumn/winter) on a quarterly basis to calculate the average sediment transport rate and intensity in each season.

\subsection{Soil Sample Collection and Analysis}

In September 2017, soil samples at depths of 0-5 cm, 5-10 cm, 10-20 cm, 20-40 cm, and 40-60 cm were collected using a soil auger (complete with a regular auger diameter of 2", a 18" rubber-coated cross handle, and a $5 / 8^{\prime \prime}$ stick, which manufactured by AMS, USA) at the study sites in three replicates. The samples were taken back to the laboratory for air drying and were evenly mixed to determine the grain size composition, using a Mastersizer 2000 (Malvern Co., British), and the organic matter and nutrients (available N/P/K, Figure 3).

\subsection{Data Analysis}

All statistical analyses were conducted using the SPSS software (version 17.0, SPSS Inc., Chicago, IL, USA). After performing one-way ANOVA, the LSD test (Least Significant Difference) for multiple comparisons was used to detect differences among plots in terms of plant shoot and root biomass. Significance was determined at the $95 \%$ confidence level $(a=0.05)$. 


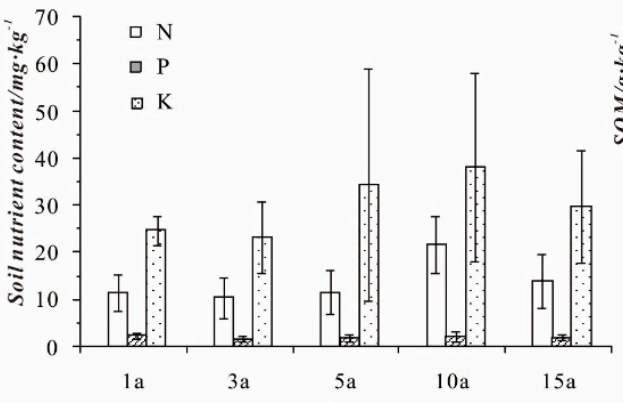

(a)

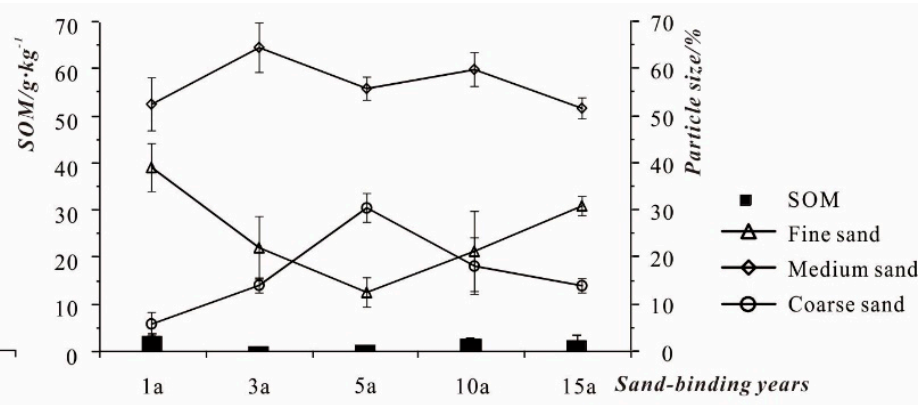

(b)

Figure 3. Soil nutrient contents (a) and the organic matter and particle sizes (b) of aged H. rhamnoides communities.

\section{Results}

\subsection{Ecological Features of Aged H. rhamnoides Communities}

\subsubsection{Community Composition}

Since the implementation of artificial measures in 2008, mobile dunes have become basically fixed or semi-fixed in WPSER. After 15 years of succession, the 15a dune became fixed, and a large amount of litter increasing top-soil fertility to reduce soil erosion, and soil evaporation provided a prosperous micro-environment for new species establishment. In the study plots, there were 20 species, belonging to six families and 14 genera, including Corydalis, Compositae, Salicaceae, Pinaceae, Leguminosae, Gramineae, and so on (Table 2). There were 17 kinds of perennial herbs, accounting for $85 \%$. Except for the planted shrubs and Avena sativa used as checkerboards, other perennial herbs were naturally recovered, like Artemisia desertorum and Oxytropis imbricata.

Table 2. Species composition of the study sites.

\begin{tabular}{cc}
\hline Family & Species \\
\hline Aphididae & H. rhamnoides \\
Compositae & Artemisia desertorum; Helianthus tuberosus; Sonchus oleraceus \\
Willow & Populus simonii; Salix cheilophila \\
Matsuko & Pinus sylvestrisvar \\
Legume & Caragana intermedia; Oxytropis imbricata \\
Gramineae & Agropyron cristatum; Poa annua; Leymus secalinus; Elymus nutansAvena sativa \\
\hline
\end{tabular}

\subsubsection{Community Diversity}

From Table 3, we can see that the $\mathrm{H}^{\prime}$ value of the $H$. rhamnoides communities was basically unchanged at 0.36 . The $\mathrm{D}$ value was the lowest in the $5 \mathrm{a}$ and $10 \mathrm{a}$ communities, but the overall difference was not significant. The 3 a community location is surrounded by mobile dunes; therefore, H. rhamnoides dominated in this community with scarce natural species. As a result of the complexity of the artificial sand-binding species planted in the plot, the diversity index of community 1a was higher due to human interference. The lack of significant differences in the diversity index values of the aged $H$. rhamnoides communities indicated that the habitat, community type, and plant species of the $H$. rhamnoides communities in different years were similar. 
Table 3. Diversity index values in different $H$. rhamnoides communities.

\begin{tabular}{cccccc}
\hline Diversity Index & 1a & 3a & 5a & 10a & 15a \\
\hline$H^{\prime}$ & $0.368^{\mathrm{a}}$ & $0.367^{\mathrm{a}}$ & $0.365^{\mathrm{a}}$ & $0.358^{\mathrm{a}}$ & $0.368^{\mathrm{a}}$ \\
$\mathrm{D}$ & $0.597^{\mathrm{a}}$ & $0.658^{\mathrm{a}}$ & $0.584^{\mathrm{a}}$ & $0.541^{\mathrm{a}}$ & $0.634^{\mathrm{a}}$ \\
$\mathrm{J}$ & $0.189^{\mathrm{a}}$ & $0.205^{\mathrm{a}}$ & $0.175^{\mathrm{a}}$ & $0.172^{\mathrm{a}}$ & $0.177^{\mathrm{a}}$ \\
\hline
\end{tabular}

Note: "a" means there were no significant differences in different $H$. rhamnoides communities.

\subsubsection{Community Structure}

The growth of $H$. rhamnoides increased as years went by, with peaks at $5 \mathrm{a}$ and $10 \mathrm{a}$. The plant height of 1 a was $50 \mathrm{~cm}$, while that of $3 a$ was only $25 \mathrm{~cm}$ as it was seriously damaged by wind erosion and sand burial from a nearby mobile dune. The north-south width was almost the same as the west-east width, which indicated that plants were similarly influenced by each wind direction. As shown in Figure 4, the height and canopy of $H$. rhamnoides increased with age to 10 years and then remained almost unchanged. The height of 10a reached 50 to $60 \mathrm{~cm}$, and the canopy width reached 65 to $70 \mathrm{~cm}$. $5 \mathrm{a}$ and 10a were the most vigorous. It is indicated that after 10 years, H. rhamnoides gradually declined and shrunk, and the community appears to have transitioned to succession.

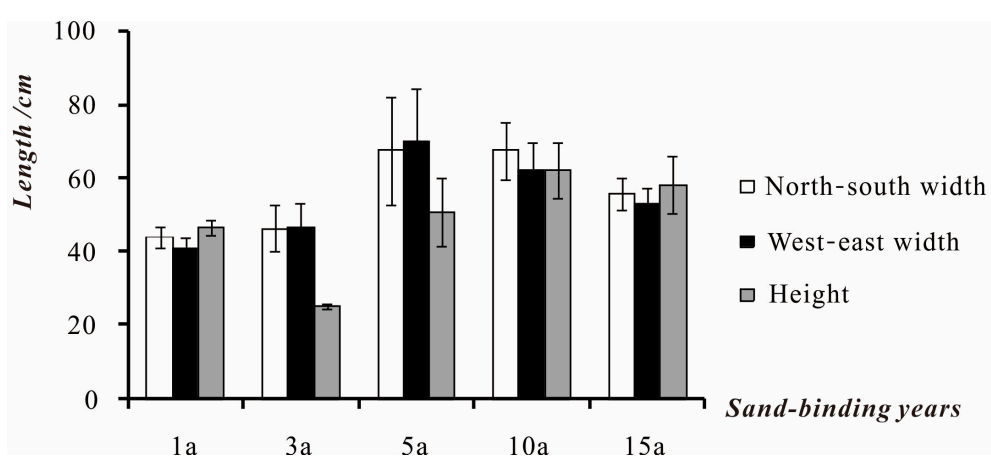

Figure 4. The heights and canopy widths of different $H$. rhamnoides communities.

The survival rate of 1a was more than 50 percent for replanted $H$. tuberosus with coverage of less than $20 \%$ in 2018 , but its survival rate reached $80 \%$ without natural vegetation. However, the survival rate of $H$. rhamnoides was up to $100 \%$ in the $3 a$ and 5 a communities, and the total coverage was $21 \%$ and $45 \%$, respectively. From Table 4, we know that the maximum coverage of 10 a reached $45.33 \%$, and the survival rate was $95 \%$. Total coverage was the highest in the 15 a dunes, but the coverage of H. rhamnoides was $36 \%$, less than that in 10a. It was also found in the field data collection that the $15 \mathrm{a}$ community was gradually replaced by $A$. desertorum, with coverage up to $25.67 \%$.

Table 4. Total coverage (\%) and shrub coverage (\%) in different $H$. rhamnoides communities.

\begin{tabular}{ccccc}
\hline Community & Total Coverage & Shrubs & Coverage & Herbs \\
\hline \multirow{4}{*}{ 1a } & \multirow{2}{*}{19.33} & H. rhamnoides & 9.33 & \\
& & A. desertorum & 4.00 & \\
& P. simonii & 2.00 & A. sativa \\
& S. cheilophila & 1.00 & \\
3a & H. tuberosus & 3.00 & \\
& \multirow{2}{*}{21.00} & H. rhamnoides & 14.33 & A.cristatum, \\
& S. cheilophila & 1.00 & O. imbricate, \\
& A. desertorum & 5.67 & E.nutans \\
\hline
\end{tabular}


Table 4. Cont.

\begin{tabular}{|c|c|c|c|c|}
\hline Community & Total Coverage & Shrubs & Coverage & Herbs \\
\hline \multirow{5}{*}{$5 a$} & \multirow{5}{*}{45.00} & H. rhamnoides & 22.00 & \multirow{5}{*}{$\begin{array}{l}\text { A.cristatum, } \\
\text { O. imbricate, } \\
\text { L. secalinus }\end{array}$} \\
\hline & & P. simonii & 15.00 & \\
\hline & & S. cheilophila & 2.00 & \\
\hline & & P. sylvestrisvar & 4.00 & \\
\hline & & A. desertorum & 2.00 & \\
\hline \multirow{4}{*}{$10 \mathrm{a}$} & \multirow{4}{*}{60.33} & H. rhamnoides & 45.33 & \multirow{4}{*}{$\begin{array}{c}\text { A.cristatum, } \\
\text { O. imbricate, } \\
\text { L. secalinus, } P \text {. annua }\end{array}$} \\
\hline & & P. sylvestrisvar & 11.00 & \\
\hline & & C. intermedia & 2.00 & \\
\hline & & A. desertorum & 2.00 & \\
\hline \multirow{3}{*}{$15 a$} & \multirow{3}{*}{65.04} & H. rhamnoides & 36.70 & A.cristatum, \\
\hline & & P. sylvestrisvar & 2.67 & O. imbricate, \\
\hline & & A. desertorum & 25.67 & L. secalinus, P. annua \\
\hline
\end{tabular}

\subsubsection{Community Biomass and Root Distribution}

From Table 5, we can see that the aboveground biomass of $H$. rhamnoides in different years was from $71 \mathrm{~g}$ to $865 \mathrm{~g}$, and the underground biomass went from about $28 \mathrm{~g}$ to $827 \mathrm{~g}$ as the years progressed. This indicated that the productivity and nutrient and water absorption capacity were significantly different among different $H$. rhamnoides communities. The biomass of $15 \mathrm{a}$ was about 10 to 30 times that of $1 \mathrm{a}$, and the aboveground biomass presented a fold increase after planting. The biomass of $5 \mathrm{a}$ was mainly concentrated in the denseness of the branches, which increased the canopy density. The data also reflected that $H$. rhamnoides gradually concentrated its root system in the 10 years after the beginning of planting, with the root biomass increasing fourfold. The root-shoot ratio of $H$. rhamnoides increased with increasing number of years, and the largest was found at 10 years since the roots of $15 \mathrm{a}$ were so long horizontally that we could not dig up all of them.

Table 5. Biomass and shoot ratios of the aged H. rhamnoides communities.

\begin{tabular}{cccccccccc}
\hline Aged & $\begin{array}{c}\text { Height/ } \\
\text { cm }\end{array}$ & Canopy/ cm & $\begin{array}{c}\text { Root } \\
\text { Height/cm }\end{array}$ & $\begin{array}{c}\text { Branch } \\
\text { Roots }\end{array}$ & $\begin{array}{c}\text { Depth of } \\
\text { Roots/cm }\end{array}$ & $\begin{array}{c}\text { Above } \\
\text { Biomass/g }\end{array}$ & $\begin{array}{c}\text { Under } \\
\text { Biomass/g }\end{array}$ & $\begin{array}{c}\text { Root-Shoot } \\
\text { Ratio }\end{array}$ \\
\hline $1 \mathrm{a}$ & 40 & 32 & 25 & - & 1 & $30-50$ & 71.30 & 28.01 & 0.39 \\
3a & 46 & 45 & 50 & 55 & 4 & $30-80$ & 285.33 & 175.00 & 0.61 \\
$5 \mathrm{a}$ & 65 & 110 & 90 & 90 & 5 & $90-150$ & 275.89 & 242.76 & 0.88 \\
$10 \mathrm{a}$ & 63 & 69 & 90 & 80 & 8 & $90-260$ & 453.96 & 885.26 & 1.95 \\
$15 \mathrm{a}$ & 54 & 103 & 78 & 55 & 6 & $100-340$ & 865.22 & 826.97 & 0.96 \\
\hline
\end{tabular}

The taproots of $H$. rhamnoides grew thicker and thicker with the increasing number of sand fixation years, with a deeper root distribution, wider horizontal extension, and rhizobia produced on the lateral roots. The root distribution depth of $H$. rhamnoides increased with time after planting, while the taproot length was the longest in $5 \mathrm{a}$, and the number of branch roots was the greatest in 10a. The roots of H. rhamnoides in 1a and 3a were distributed in the top 0-60 cm soil layer with medium-fine roots rather than medium-thick roots. The roots in 10a were up to $260 \mathrm{~cm}$ deep, and those in 15a were deeper than $340 \mathrm{~cm}$; in addition, they grew horizontally to $220 \mathrm{~cm}$ and $345 \mathrm{~cm}$, respectively (Figure 5). This indicated that $H$. rhamnoides had the strongest productivity and strong growth 10 years after planting. The roots of $H$. rhamnoides were highly germinated and had a wide range of horizontal extensions to the surrounding area, called clonality. On the roots of $15 \mathrm{a}$, new H. rhamnoides began to sprout. 


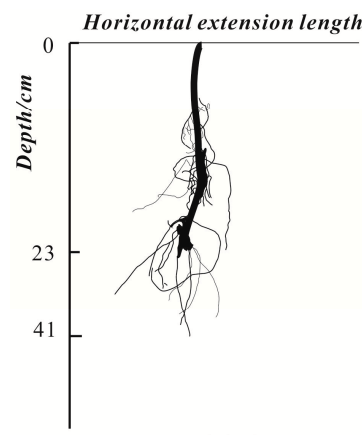

(a) $1 \mathrm{a}$

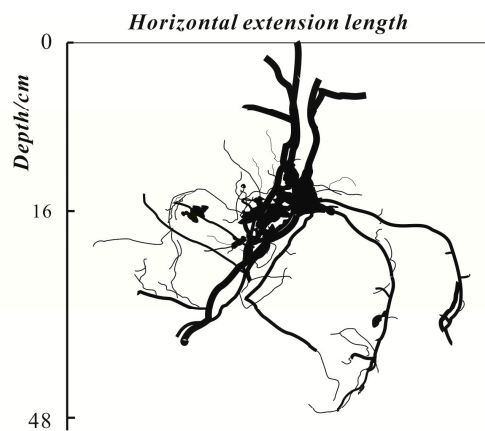

(b) $3 \mathrm{a}$

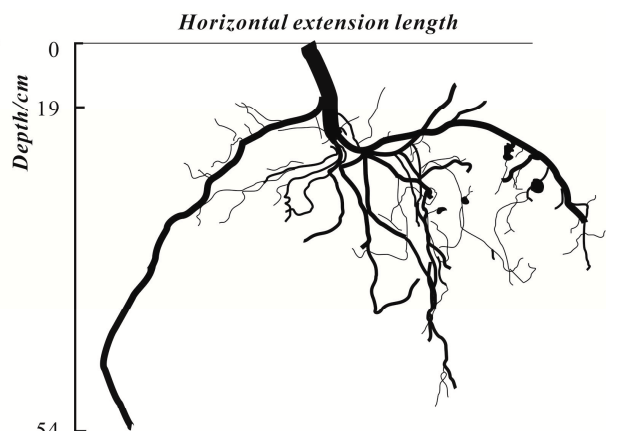

(c) $5 \mathrm{a}$

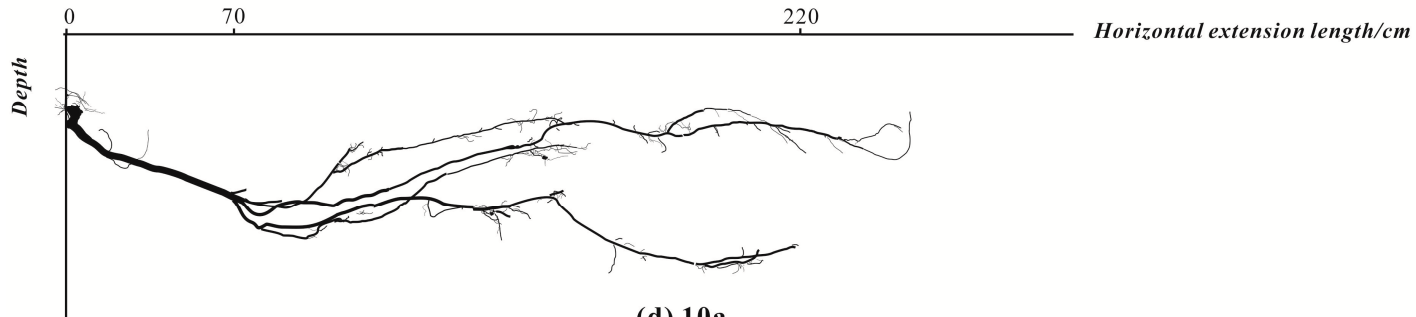

(d) 10a

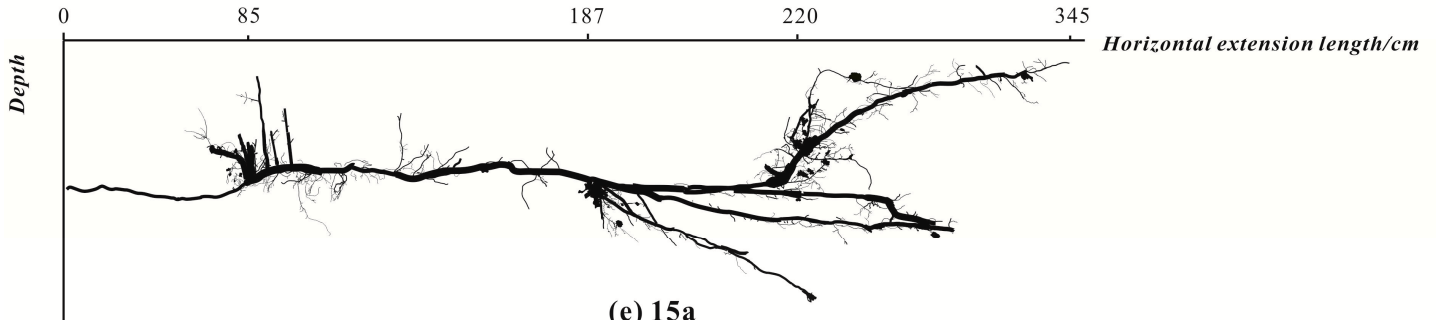

(e) $15 \mathrm{a}$

Figure 5. The root distributions in different years of H. rhamnoides.

\subsection{Aeolian Activities of H. rhamnoides Communities}

\subsubsection{Wind Speed Characteristics of the Study Sites}

At the height of $0.5 \mathrm{~m}$, the wind velocity varied slightly in the range of 0 to $1 \mathrm{~m} \cdot \mathrm{s}^{-1}$ due to the blocking effect of plants near the surface (Figure 6a). However, at the height of $2 \mathrm{~m}$, the variation in the wind speed across different dunes was relatively large and showed obvious seasonal changes (Figure $6 \mathrm{~b}$ ). The lowest wind speed was found on the $5 \mathrm{a}$ and 10a dunes. The wind velocity presented a decreasing trend with increasing plant age across the first 10 years, and then increased for plants aged 15 years; March was an exception to this, with the strongest wind in the whole year.

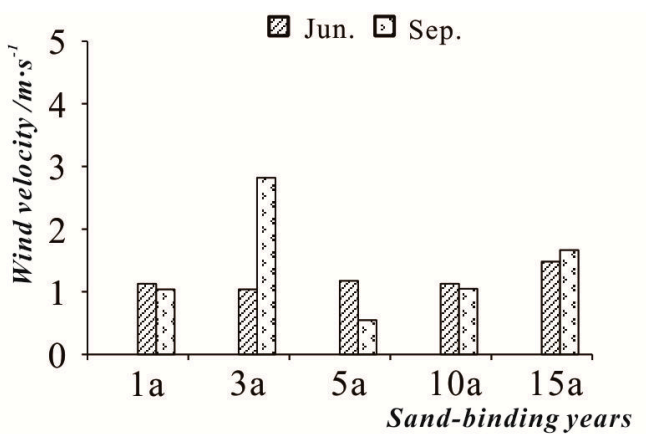

(a) Height of $0.5 m$ (under canopy)

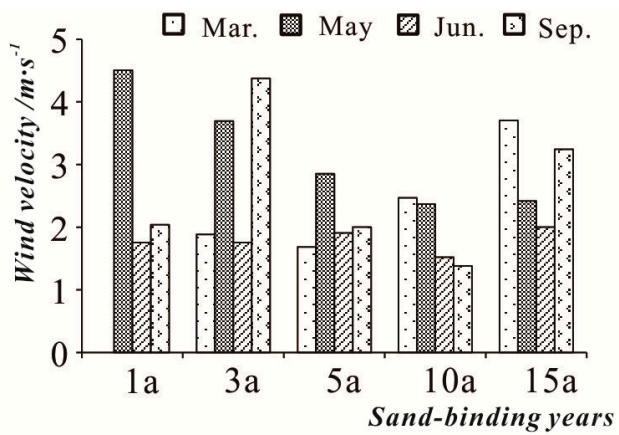

(b) Height of $2 m$ (above canopy)

Figure 6. Wind environment for different ages of $H$. rhamnoides communities. 


\subsubsection{Vertical Wind Increase Rate (R)}

Calculating the wind velocity increase rates for two levels of different dunes (bottom: $0-1 \mathrm{~m}$, upper: $1.0-2.0 \mathrm{~m}$ ) (see Table 6) resulted in different values of $\mathrm{R}$. The wind speed of the upper layer at the shifting dune was obviously increased at three times that of the low layer. In the early stage of replanting, wind speed at the upper level was obviously weakened due to surface sand barriers. However, with the passing of treatment years, the community structure became stable, and the upper-layer wind speed began to increase. When combined with the previous investigation of the growth potential of H. rhamnoides, this variation law echoes the height variation, that is, wind velocity decreases at its corresponding height. This shows that vegetation cover blocks aeolian activities, and the effect of reducing wind kinetic energy is obvious. With the increase of the growth period of H. rhamnoides, the vegetation community gradually recovered, and the restoration of the vegetation community played a role in weakening the wind speed for the entire sand dune.

Table 6. Wind velocity increase rates $\left(\mathrm{R}, \mathrm{m} \mathrm{s}^{-1}\right)$ at different heights in H. rhamnoides communities.

\begin{tabular}{ccccccc}
\hline Height Layer/m & $\mathbf{L S D}^{\mathbf{1}}$ & $\mathbf{1 a}^{\mathbf{2}}$ & $\mathbf{3 a}^{\mathbf{2}}$ & $\mathbf{5 a}^{\mathbf{2}}$ & $\mathbf{1 0 a}^{\mathbf{2}}$ & $\mathbf{1 5 a}^{\mathbf{2}}$ \\
\hline $0-1$ & 0.62 & 1.66 & 2.39 & 0.04 & 0.61 & 1.26 \\
$1-2$ & 2.00 & 0.29 & 0.36 & 0.97 & 0.45 & 1.62 \\
\hline
\end{tabular}

${ }^{1}$ LSD means mobile dune. ${ }^{2}$ 1a, 3a, 5a, 10a, 15a represents planted one year, three years, five years, ten years, and fifteen years, respectively.

\subsubsection{Sediment Transport}

The amounts of surface sediment at the different $H$. rhamnoides plots in winter were greater than those in spring and summer and decreased as the number of planting years increased (Figure 7). Except for the 3a plot, the amount of sediment in the plots was almost the same, arrayed as $3 a>5 a>$ $1 \mathrm{a}>10 \mathrm{a}>15 \mathrm{a}$. Due to the fact that the 3a plot was located in an area surrounded by mobile dunes, community cover and species diversity were low and aeolian activities were strong. According to our field investigation, many of the H. rhamnoides plants were subject to wind erosion and sand burial, so the height and canopy width of these H. rhamnoides were smaller than those at other sites. This echoed the conclusions of our study on the height, canopy, and biodiversity of H. rhamnoides and indicated that surface vegetation coverage could greatly reduce the movement of sand.

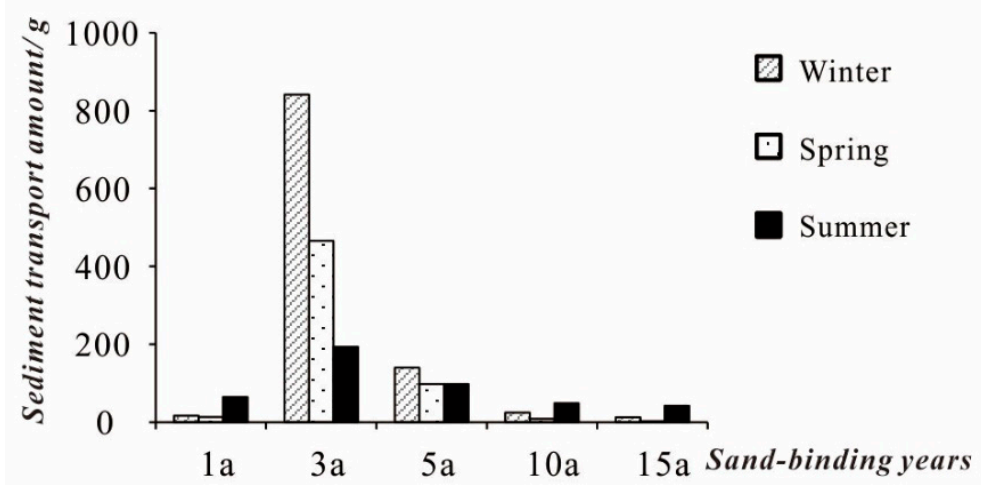

Figure 7. Sediment transport amounts at the H. rhamnoides communities (collected by bottles).

\section{Discussion}

\subsection{H. rhamnoides Community Evolution}

According to the evolution of typical sand-binding plant H. rhamnoides communities in WPSER (Table 3, Table 4, and Figure 3), it can be seen that each community has dominant species and biodiversity related to the stability of the community. With the increasing number of fixing years, the 
ecosystem effects become more and more obvious. General natural threats and moderate biological disturbance cannot destroy the stability of the community, but severe short-term effects like drought, waterlogging, dust, and artificial economic activities lead to community devastation [21,22]. For example, the 15-year-old Salix community in Shazhuyu sandy land was enriched in water after waterlogging; almost all species died and could not be restored. However, semi-fixed and fixed dunes planted with $H$. rhamnoides can maintain community growth for nearly 10 years. Even in the case of wind-induced plaque in some semi-fixed dunes, there has been effective restoration by replanting and management in recent years in WPSER.

As usual, a simple community with fewer species is more susceptible to external disturbances, but this does not mean that higher biodiversity produces a more stable community. In artificial plant communities, the number of species and biodiversity are improved in a short period of time, but the coexistence mechanisms and competitiveness of species affect community stability [23,24]. In the theory of redundancy, the versatility and parallel combinations of species within a community are the keys to maintaining community stability. When functions are consistent, and resource requirements are heterogeneous, even if a species is missing, other species can effectively compensate [25-27]. When there are concentrated ecological types, ecologically identical species, and different ecological functions in the community, invasive species will occupy a large amount of space and resources, which promotes the attenuation of important species and decay of ecological processes. Once important species are destroyed, the community will have difficulty in maintaining the original ecological function. In WPSER, S. cheilophila would not survive in a mixed community of P. euphratica and S. cheilophila. It is difficult to have P. sylvestris and C. intermedia in fixed dunes planted with $H$. rhamnoides due to the inconsistent ecological functions of the above- and underground ecological functions triggering survival of the fittest.

The return of leaves to the topsoil is a non-negligible factor in the nitrogen fixation capacity of plants. At the same time, H. rhamnoides roots can form nodules in the early stage of individual development. When a taproot is $15 \mathrm{~cm}$ long, nodules can form on the taproot and the first lateral root, and this ability is gradually enhanced as time goes on. In addition, nodules not only fix nitrogen in the air but also promote mineral organic matter, poorly soluble inorganic compounds, and organic compounds in the soil nutrient pool into an effective state, which is beneficial to plant absorption and utilization [28]. Root nodulation is a biological basis for the vigorous growth of $H$. rhamnoides in that only well-grown plants have strong nodulation ability [29]. H. rhamnoides is often used as a sand-fixing pioneer species for four main reasons: First, its roots can be symbiotic with Frankia bacteria, which can solve the problem of resource poverty in a desert. The second is its cloning habit for expanding the population and occupying new territories in harsh habitats in a rooted manner. The third is cloning behavior, which provides physiological integration functions such as resource sharing and risk self-bearing to adapt to harsh habitats and enhance stress resistance. Fourthly, its root system is highly divided; the first roots store rainwater, and secondary roots mainly absorb and transform soil water, thus alleviating the contradiction between water shortage and water retention in arid areas [30].

Compared with the sand-binding plants used in the ecological restoration process in other deserts in China, alpine desert plants show three unique characteristics. First, sand-binding plants grow rapidly in the early stage (within three years), and their sand-fixing function is significant. However, plant growth and biodiversity are limited in the middle and late stages [31,32]. Second, the ecological restoration function of the sand-binding plants is mainly reflected in wind and sand fixing, followed by natural vegetation restoration, and the ecosystem effects of water conservation, microclimate, and soil improvement are limited. Thirdly, different types of dunes can be configured with different patterns of mixed shrubs and different techniques such as seedlings, branch cuttings, and seeding, or deep-planting. Methods like fencing, sand barrier protection, and replanting can be used to repair mobile dunes, and H. rhamnoides is the perfect pioneer species in alpine desertification control [33]. 


\subsection{Effects of Aeolian Activities on H. rhamnoides Communities}

The 1a H. rhamnoides plots theoretically have few species, with low biodiversity and few natural restoration species. However, due to the subsequent large-scale planting of Jerusalem artichoke, the community coverage was almost the same as that of the 3a community. So, surface sediments were significantly finer, and the SOM (soil organic matters) was greater (Figure 3); in particular, aeolian activities were weakened even below the levels in the 3a community (Figure 7). This special case gives us a new line of thinking that a good combination of shrubs and perennial herbs can provide better ecological benefits in a desert. 10a had the highest height, canopy width, community coverage, and shrub cover, while its SOM, N, P, and K content and root-shoot ratio were also the highest, so it had the most vigorous productivity. However, 15a had the highest biomass, the deepest and widest root distribution, and the strongest wind-sand protection ability. Lu et al. [34] proposed that biomass increases year by year during the growth period. The fastest growth period was the first four to five years, and the growth was the highest at nine years and then decreased. It was also noted in our field observations that the mother plants of 15 a showed a trend of decay, and some died. However, the regeneration ability became stronger with nascent seedling roots growing out from horizontal roots. Therefore, in desertification control work in alpine deserts, $H$. rhamnoides should be reared and renewed after 10 years to maximize the use of land resources and restore ecological benefits.

For strong sand flow, on the one hand, plants adopt an avoidance strategy to distribute more energy to their underground biomass and enhance the lateral growth of the canopy rather than longitudinal growth [16]. H. rhamnoides also forms a low and round crown shape to reduce wind force, and a wax layer and fine blade plush leaves to avoid direct damage from the sand flow $[35,36]$. On the other hand, desert plants can adopt a resistance strategy by strengthening the growth of rhizomes; roots are deepened, and the horizontal development of lateral roots strengthens the resistance of plants to wind and sand [36]. In addition, alpine sand-binding plants reduce stomatal conductance and water evaporation from the leaves under strong winds, strengthen the reproductive growth of adventitious roots under the action of sand burial, and improve wind-sand protection by using regular and reasonable afforestation spacing, density, and morphology when planting $[37,38]$. Through wind erosion corridors and sand-fixed piles, an erosion-deposit balance in the surface of sand dunes can be achieved. Although $H$. rhamnoides has significant wind and sand fixation benefits and has the adaptability to wind erosion and sand burial, it suffers from strong aeolian activities at the early stages of plant growth, directly affecting the survival rate and preservation rate. Subsequent long-term wind-sand stress has inevitable effects on the growth and reproduction of plants, which leads to a decrease in density and the coverage of dunes and, in turn, strengthens the local aeolian activities. This cyclical negative feedback is the main cause of the high death rate and low growth of $H$. rhamnoides in alpine deserts [17]. However, in the early stage of transplanting, there is long-term protection from straw checkerboard sand barriers and a reasonable afforestation density. The survival rates and preservation rates of $H$. rhamnoides are always above $90 \%$, and mobile dunes are transformed into fixed ones after two to three years. The annual sediment transport rate and accumulation depth are smaller than those for other plots, which also promotes the settlement of herbaceous species and shrubs and increases community diversity. Therefore, in order to ensure the survival, growth, and community succession of $H$. rhamnoides, we need to pay attention to laying mechanical sand barriers with different specifications and forms when transplanting via the "three steps and one burial" procedure and to strengthening replanting work after transplantation. Moreover, it is necessary to mix with other herbs or shrubs.

From the results, we know that the species composition became more abundant, and the plant height, community coverage, biodiversity, and biomass increased as the number of binding years increased. At the same time, the presence of plants reduced wind flow in the upper part of the plants; the more fixation years, the lower the surface sediment transport. Our results will provide theoretical support for alpine desertification management and governance planning of the Qinghai Lake Basin. However, we only paid attention to the qualitative relationship between vegetation and 
aeolian activities in this manuscript. It is not enough to qualitatively evaluate the effect of plantations. Therefore, in future work, we will try to find quantitative relationships between vegetation and aeolian activities, such as the correlation between vegetation height, coverage, and wind velocity, and the responses of aged plantations to the same wind speed.

\section{Conclusions}

The climate in the alpine desert regions is extremely harsh, and plants grow slowly. After $H$. rhamnoides were planted in mobile dunes, they were gradually fixed. With the increasing number of binding years, the species composition became more abundant, natural vegetation began to recover, and biodiversity increased year by year. At the same time, the plant height, canopy width, and coverage increased, but $H$. rhamnoides coverage was reduced after 10 years as coverage of $A$. desertorum increased. The biomass of $H$. rhamnoides increased significantly, the underground biomass in particular. The taproot was thickened year by year, and it grew to a depth of $1 \mathrm{~m}$, while the horizontal extensions reached more than $3 \mathrm{~m}$. The roots of $H$. rhamnoides have strong sprouting ability, and new branches were grown on horizontal roots. Plants are a useful obstacle to aeolian activity. The presence of plants reduced the wind in the upper parts of the plants, but it did not have obvious regular characteristics. We observed lower amounts of sediment transport with the increasing number of fixation years. It is significant that sediment transport in winter is larger than that in spring and summer. In extremely cold winters the wind velocity is very strong (so-called Buran, because high pressure is located in central-Asia); therefore, the sediment transport is also stronger in winter. After 15 years of binding, $H$. rhamnoides grow well in the study area, and the community is still stable.

Author Contributions: Conceptualization-L.T.; methodology-X.Z. and W.W.; software-H.W. and Q.W.; validation-D.Z. and L.T.; formal analysis-X.Z.; investigation-X.Z.; resources-W.W.; data curation-L.T.; writing-original draft preparation-L.T.; writing—review and editing-W.W. and Y.Y.; visualization-D.Z.; supervision-D.Z.; project administration-L.T.; funding acquisition-L.T. and D.Z.

Funding: This research was funded by Natural Science Foundation of China (41961017, 41661001), Qinghai Three Rivers Ecological Protection and Construction Phase II (2018-S-1), Science and Technology Project of Qinghai Province (2018-NK-A3, 2016-ZJ-Y01), The Open Project of State Key Laboratory of Plateau Ecology and Agriculture, Qinghai University (2017-ZZ-10; 2018-KF-03) and Thousand High Innovative Talents Program of Qinghai Province. Yang Yu received the young elite scientist sponsorship program by China Association for Science and Technology (2017 to 2019).

Conflicts of Interest: The authors declare no conflict of interest.

\section{References}

1. Sperry, J.S.; Hacke, U.G. Desert shrub water relations with respect to soil characteristics and plant functional type. Funct. Ecol. 2002, 16, 367-378. [CrossRef]

2. D'Odorico, P.; Bhattachan, A.; Davis, K.F.; Ravi, S.; Runyan, C.W. Global desertification: Drivers and feedbacks. Adv. Water Resour. 2013, 51, 326-344. [CrossRef]

3. Qi, Y.; Chen, T.; Pu, J.; Yang, F.; Shukla, M.K.; Chang, Q. Response of soil physical, chemical and microbial biomass properties to land use changes in fixed desertified land. Catena 2018, 160, 339-344. [CrossRef]

4. Yu, Y.; Jia, Z.Q. Changes in soil organic carbon and nitrogen capacities of Salix cheilophila Schneid. along a revegetation chronosequence in semi-arid degraded sandy land of the Gonghe Basin, Tibetan Plateau. Solid Earth 2014, 5, 1045-1054. [CrossRef]

5. Li, X.R.; Zhou, H.Y.; Wang, X.P.; Liu, L.C.; Zhang, J.G.; Chen, G.X.; Zhang, Z.S.; Liu, Y.B.; Tan, H.J.; Gao, Y.H. Ecological restoration and recovery in arid desert regions of China: A review for 60-year research progresses of Shapotou Desert Research and Experiment Station, Chinese Academy of Sciences. J. Desert Res. 2016, 36, 247-264.

6. Pearson, M.; Rogers, J. Hippophae rhamnoides L. J. Ecol. 1962, 50, 501-513. [CrossRef]

7. Richards, E.; Burningham, H. Hippophae rhamnoides on a coastal dune system: A thorny issue? J. Coast. Conserv. 2011, 15, 73-85. [CrossRef] 
8. Chen, B.B.; Zeng, C.; Gao, H.Y.; Liu, C.H.; Li, G.Q.; Dai, G.H. Response of persistence of Hippophae rhamnoides L. to soil water contents. J. Cent. South Univ. For. Technol. 2016, 36, 67-71.

9. Zuazo, V.H.D.; Pleguezuelo, C.R.R. Soil-erosion and runoff prevention by plant covers: A review. Sustain. Agric. 2008, 28, 65-86.

10. Brown, J.F. Effects of experimental burial on survival, growth and resource allocation of three species of dune plants. J. Ecol. 1997, 85, 151. [CrossRef]

11. Li, X.R.; Zhang, Z.S.; Huang, L.; Wang, X. Review of the ecohydrological processes and feedback mechanisms controlling sand-binding vegetation systems in sandy desert regions of China. Chin. Sci. Bull. 2013, 58, 1483-1496. [CrossRef]

12. Yu, Y.J.; Shi, P.J.; He, L.P. Research on the effects of wind-sand current on the plant growth. Adv. Earth Sci. 2002, 17, 262-267.

13. Maun, M.A.; Lapierre, J. The effects of burial by sand on Ammophila breviligulata. J. Ecol. 1984, 72, 827-839. [CrossRef]

14. Zhang, J.H.; Maun, M.A. Effects of sand burial on seed germination, seedling emergence, survival, and growth of Agropyronp sammophilum. Can. J. Bot. 1990, 68, 304-310. [CrossRef]

15. Wu, W.Y.; Zhang, D.S.; Tian, L.H.; Zhang, M.Y.; Zhou, X. Ecological responses of Hippophae rhamnoides to wind-sand hazard in alpine sand land. Bull. Soil Water Conserv. 2018, 38, 1-8.

16. Zhang, D.S.; Tian, L.H.; Lu, R.J.; Tang, Q.L.; Shi, H. Grain-size features of aeolian deposits in the eastern shore of Qinghai Lake. Arid Land Geogr. 2013, 36, 203-211.

17. Wu, W.Y.; Zhang, D.S.; Tian, L.H.; Zhang, M.Y.; Zhou, X. Features of artificial plant communities from the east sand region of the Qinghai Lake over the last 10 years. Acta Ecol. Sin. 2019, 39, 2109-2121.

18. Wu, H.W.; Li, X.Y.; Jiang, Z.Y.; Chen, H.Y.; Zhang, C.C.; Xiao, X. Contrasting water use pattern of introduced and native plants in an alpine desert ecosystem, northeast Qinghai-Tibet Plateau, China. Sci. Total Environ. 2016, 542, 182-191. [CrossRef]

19. Wu, Z. Geomorphology of Wind-Drift Sands and Their Controlled Engineering; China Science Publishing \& Media Ltd.: Beijing, China, 2003; pp. 61-86.

20. Odum, E.P.; Barrett, G.W. Fundementals of Ecology, 5th ed.; Brooks/Cole: New York, NY, USA, 2005; pp. 33-35.

21. Liu, H.T. Study on eco-physiological characteristics of Salix Cheilophila and Process of Vegetation Restoration in Alpine-Cold Sandy Land; Chinese Academy of Forestry: Beijing, China, 2012.

22. Ma, Q.L.; Lu, Q.; Zhang, D.K.; Liu, H.J.; Jin, H.J. Wind prevention and sand resistance effects of Artemisia sphaerocephala and A. ordosica. Chin. J. Ecol. 2012, 31, 1639-1645.

23. Grimm, V.; Wissel, C. The ecological stability discussions: An inventory and analysis of terminology and a guide for avoiding confusion. Ecology 1997, 109, 323-334. [CrossRef]

24. McCann, K.S. The diversity-stability debate. Nature 2000, 405, 228-233. [CrossRef] [PubMed]

25. Li, D.Y. Redundancy theory and its application to Ecology. J. Nantong Univ. 2006, 5, 55-59.

26. Cao, C.; Zhu, L.; Jiang, D.; Fan, S. Discussion on Mechanism of Stability of Sand-fixing Phytocoenosium. J. Desert Res. 2004, 24, 461-466.

27. Hill, A.R. Ecosystem stability in relation to stresses caused by human activities. Can. Geogr. 1975, 19, $206-220$. [CrossRef]

28. Li, R.X.; Xue, Q.H.; Yang, S.Y.; Feng, L.X.; Zhou, X.S. Improving effect of Seabuckthorn and Black Locust artificial forests to soil fertility in Loess Plateau and its model. J. Soil Eros. Soil Water Conserv. 1998, 4, 14-21.

29. Li, G.Q.; Tang, R.D.; Zhao, Y.Q. The Biological property and ecological habit of Hippophae. Acta Bot. Boreali Occident. Sin. 2000, 20, 892-897.

30. Wang, L.; Zhang, X.M.; Lin, M.Z.; Zhang, J.K. Study on root and function of Hippophae I-Root differentiation and division. Hippophae 2005, 4, 13-19.

31. Song, C.Y.; Guo, K.; Liu, G.H. Relationships between plant community's species diversity and soil factors on otingdag sandy land. Chin. J. Ecol. 2008, 27, 8-13.

32. Li, Y.H.; Luo, T.X.; Lu, Q.; Tian, X.Y.; Wu, B.; Yang, H.H. Comparisons of leaf traits among 17 major plant species in shazhuyu sand control experimental station of Qinghai Province. Acta Ecol. Sin. 2005, 25, 994-999.

33. Yang, Z.W. Discussion on three modes of desertification control in Qinghai alpine arid area. Sci. Technol. Qinghai Agric. For. 2004, 3, 42-45.

34. Lu, Z.X.; Meng, H.J.; Yan, C.M. Study on the growth of Seabuckthorn and its improvement of soil properties. Gansu Sci. Technol. 2016, 10, 226-227. 
35. Walter, B.; Voegeli, C.; Horender, S. Estimating sediment mass fluxes on surfaces sheltered by live vegetation. Bound. Layer Meteorol. 2017, 163, 273-286. [CrossRef]

36. Li, S.L.; Werger, M.J.; Zuidema, P.A.; Yu, F.H.; Dong, M. Seedlings of the Semi-shrub Artemisia ordosica are Resistant to Moderate Wind Denudation and Sand Burial in Mu Us Sandland, China. Trees 2010, 24, 515-521. [CrossRef]

37. Danjon, F.; Fourcaud, T.; Bert, D. Root architecture and wind-firmness of mature Pinus pinaster. New Phytol. 2005, 168, 387-400. [CrossRef] [PubMed]

38. Nicoll, B.C.; Ray, D. Adaptive growth of tree root systems in response to wind action and site conditions. Tree Physiol. 1996, 16, 891-898. [CrossRef] [PubMed]

(C) 2019 by the authors. Licensee MDPI, Basel, Switzerland. This article is an open access article distributed under the terms and conditions of the Creative Commons Attribution (CC BY) license (http://creativecommons.org/licenses/by/4.0/). 